ORIGINAL ARTICLE

\title{
Asymptomatic Malaria Infection and Associated Factors among Blood Donors Attending Arba Minch Blood Bank, Southwest Ethiopia
}

\author{
Getaneh Alemu', Mohammedaman Mama ${ }^{1}$
}

\footnotetext{
OPEN ACCESS

Citation: Getaneh Alemu,

Mohammedaman Mama. Asymptomatic

Malaria Infection and Associated Factors among Blood Donors Attending Arba Minch Blood Bank, Southwest Ethiopia. Ethiop J HealthSci.2018;28(3):315.

doi:http://dx.doi.org/10.4314/ejhs.v28i3.9

Received: December 3, 2017

Accepted: December 6, 2017

Published: May 1, 2018

Copyright: (C) 2018 Getaneh Alemu, et al

. This is an open access article distributed under the terms of the Creative Commons Attribution License, which permits unrestricted use, distribution, and reproduction in any medium, provided the original author and source are credited. Funding: Arba Minch University

Competing Interests: The authors declare that this manuscript was approved by all authors in its form and that no competing interest exists.

Affiliation and Correspondence:

${ }^{1}$ Department of Medical Laboratory Science, Arba Minch University, Arba Minch, Ethiopia

*Email:getanehmlt@gmail.com/getane

h.alemu@amu.edu.et
}

\section{ABSTRACT}

BACKGROUND: It is well known that malaria can be transmitted via blood transfusion. However, it is not documented in the national donor screening protocol. Magnitude of asymptomatic malaria among donors would be the key to decide on the need of donor screening. Despite this, there is lack of such data in Ethiopia. The aim of this study was thus to estimate the prevalence of asymptomatic malaria and associated factors among blood donors.

METHODS: An institution basedcross-sectional study was conducted in Arba Minch blood bank from February to June, 2015. Data was collected from donors who passed the clinical donor selection criteria and recruited by systematic random sampling technique. A structured questionnaire was used to capture data on socio-demographic characteristics. Giemsa stained blood films were examined for plasmodium parasites. Magnitude of asymptomatic malaria was calculated and association of factors with malaria was assessed by multivariable logistic regressions using SPSS version 20.0.

RESULTS: A total of 416 donors participated in the study. The proportion of infected donors was 4.1\% (17/416). Eight donors were infected with Plasmodium falciparum while 9 donors were infected with Plasmodium vivax. Most positive blood films (13/17) were with parasite loads ranging from 100 - 500 parasites/ $\mu$ l. Donors with blood group $O$ were more susceptible to malaria parasitemia compared to all other $A B O$ blood groups together ( $A O R=6.899,95 \% C I=1.951-24.391, p=0.003)$.

CONCLUSION: Magnitude of malaria parasitemia in the present study was high as compared to the national malaria prevalence. Hence, in malaria endemic areas of Ethiopia, blood should be screened before donation.

KEYWORDS: Blood transfusion, malaria prevalence, blood donor 


\section{INTRODUCTION}

Malaria is one of the major public health problems worldwide affecting around 91countries and territories (1). It is caused by a protozoan parasite of the genus Plasmodium $(2,3)$. The disease is widespread in hot humid regions of Africa, Asia, and South and Central America. It also occurs in many temperate regions $(4,5,6)$. In 2015, 212 million malaria cases occurred globally leading to 429,000 deaths. Sub-Saharan Africa is the most affected region, accounting for 90.1\% (191 million) of the cases and $91.8 \%$ (394 thousand) of the deaths in 2015 (1).

Malaria is one of the three leading causes of morbidity in Ethiopia $(7,8)$. In 2015 , a total of 1,867,059 laboratory confirmed cases and 662 deaths were reported in the country. Four plasmodium species have been reported in Ethiopia among which $P$. falciparum and $P$. vivax are responsible for $64 \%$ and $36 \%$ of the malaria cases, respectively (1). P.falciparum and P. vivax are commonly reported in Arba Minch with no data to substantiate the proportion (unpublished data).

Plasmodium parasites are transmitted primarily by female Anopheles mosquitoes (9). Blood transfusion, organ transplantation and transplacental and needle injury are also possible routes of transmission (10). Transfusion transmitted malaria (TTM) occurs commonly in malaria endemic countries andcontinues to hamper efforts of malaria control $(3,11)$. Blood donors in sub-Sahara African countries are likely to be infected with malaria parasites and contribute to the transmission of the disease (12-20).

The World Health Organization (WHO) recommended screening of blood donations for malaria based on local epidemiological evidences (21). Although $60 \%$ of the population is exposed to malaria, laboratory screening for malaria is not currently performed in Ethiopia (22). Laboratory screening is not practiced so far with the possible reasons of fear of increased donor deferral, urgency of blood needed by recipients compared to health impact of TTM and the cost of screening (unpublished data).
Adequate data from different geographical settings of the country is needed to be an input for the Federal Ministry of Health to make decisions about donor blood screening. However, there is lack of data about the magnitude and factors related to asymptomatic malaria among donors in Ethiopia. Hence, the aim of this study was to estimate the prevalence of asymptomatic malaria and associated factors among blood donors attending Arba Minch blood bank.

\section{MATERIAL AND METHODS}

Study design and area: A facility based crosssectional study was conducted in Arba Minch blood bankf rom February to June 2015. Arba Minch is located at $454 \mathrm{kms}$ south of Addis Ababa. It is found at an altitude of 1200-1300 meters above sea level with an average annual temperature of $29.7^{\circ} \mathrm{C}$ and rain fall of $900 \mathrm{~mm}$ (23). Arba Minch blood bank is one of the three blood banks found in South Nations, Nationalities and Peoples Region of Ethiopia. The blood bank at average collects 375 units of blood per month from volunteer donors. Only whole blood is donated to recipients after screening for hepatitis $\mathrm{B}$ and $\mathrm{C}, \mathrm{HIV}$ and syphilis. Non-febrile donors who did not contact malaria (based on donor selfreport) within the last six months are accepted for donation without laboratory screening.

Source and study population: All adult population with eligible age range (17-65 years old) for blood donation and living in malaria endemic catchment areas of Arba Minch blood bank were the source population. The study subjects were recruited among those who came to donate blood during the study period.

Sample size and sampling technique: The sample size was determined using single population proportion formula $\left(\mathrm{n}=[\mathrm{Z} 1-\alpha / 2]^{2} \mathrm{P}\right.$ $\left.(1-\mathrm{p}] / \mathrm{d}^{2}\right)$ at $95 \%$ confidence level $(\mathrm{Z}(1-\alpha) / 2)=$ 1.96). A 5\% marginal error (d) was tolerated. Since there are no previous data about the prevalence (p) of malaria among blood donors in the area, we considered $50 \%$ prevalence for sample size calculation. Substituting the values, calculated sample size was 384 , and the final

DOI: http://dx.doi.org/10.4314/ejhs.v28i3.9 
sample size was 423 after adding $10 \%$ to compensate for non-respondents. Systematic random sampling technique was followed. By tracing back last year's donor flow, we expected 1650 donors during the study period. Therefore, calculated $\mathrm{K}$ value was $4(1650 / 423)$. The first participant was selected by lottery method and then every fourth donor was recruited.

Inclusion and exclusion criteria: The inclusion criterion was passing the screening criteria of the blood bank. The exclusion criterion was being permanent resident of known non-endemic area for malaria.

Socio-demographic data: Nurses who are fluent speakers of the local language (Gamogna) were selected and trained for data collection. Sociodemographic data was collected using a pretested structured questionnaire administered through face-to-face interview after it was translated in to the local language. Participants were also interviewed for their history of malaria infection, treatment received and history of previous blood donation.

Laboratory methods: We used blood collected into the tube part of the blood bag for blood film preparation. Both thin and thick blood films were prepared and examined after staining with Giemsa (24). For positive samples, asexual stages of malaria parasites were counted against 500 white blood cells (WBC) on the thick film and reported as number of parasites per $\mu \mathrm{l}$ of blood assuming a standard adult leukocyte count of $8000 / \mu 1$.

No. of Parasites $/ \mu$ of blood $=($ WBC counts $X$ parasites counted against 500WBC)/500

Where: $\mathrm{WBC}$ counts $=8000 / \mu 1(25)$.

A blood smear was regarded negative after examining a minimum of 200 high power fields with no parasites seen. All laboratory procedures were processed in Arba Minch blood bank laboratory by trained laboratory technologists. Standard operating procedures were strictly followed for malaria diagnosis. Giemsa stalk solution was stored appropriately and the staining quality was checked every week by processing known positive and negative samples. The $\mathrm{ABO}$ and $\mathrm{Rh}$ blood groups of donors were taken from the donors' registration book. Investigators supervised all aspects of data collection.

Statistical analysis: Data were entered and analysed using SPSS version 20.0. Descriptive statistics like frequency, median and percentage were calculated to describe the study population characteristics. Bivariate logistic regression was used for assessing general associations between categorical variables. Multivariable logistic regression analysis then followed for variables with $\mathrm{p} \leq 0.25$ in the bivariate analysis. Association between variables was considered statistically significant only if $\mathrm{P}$-value $\leq 0.05$ at $95 \%$ confidence level.

Ethical approval and consent to participate: Ethical approval for the research was granted by review boards of Arba Minch University College of Medicine and Health Sciences with a project code of Gov/AMH/5-1/CMHS/MLS/01/07. Official permission letter was also obtained from Arba Minch blood bank. Written consent was obtained from all participating blood donors. All laboratory results were communicated to study subjects promptly. All malaria positive blood was discarded.

\section{RESULTS}

A total of 418 (response rate $=98.82 \%$ ) blood donors participated in the study, and data collected from 416 (232 male and 184 female) participants were complete for analysis. The median age of participants was $22 \pm 0.29$ (Median \pm SEM) with a range of 18-59 years. Donors with self-reported malaria history were $154(37 \%)$. Only $152(36.5 \%)$ participants slept under bed net. All the participants were volunteer blood donors, and 219 $(52.6 \%)$ of them had previous history of donation. The most frequent blood group was $\mathrm{O}(175$; $42.1 \%)$, followed by bllod group A $(136 ; 32.7 \%)$ (Table 1). 
Table 1: Socio-demographic characteristics and clinical history of blood donors attending Arba Minch blood bank from February to June 2015

\begin{tabular}{|c|c|c|}
\hline Variables & & Number $(\%)$ \\
\hline \multirow[t]{2}{*}{ Sex } & Male & $232(55.8)$ \\
\hline & Female & $184(44.2)$ \\
\hline \multirow[t]{3}{*}{ Age group } & $18-27$ & $355(85.3)$ \\
\hline & $28-37$ & $48(11.6)$ \\
\hline & $>37$ & $13(3.1)$ \\
\hline \multirow[t]{2}{*}{ Marital status } & Single & $339(81.5)$ \\
\hline & Married & $77(18.5)$ \\
\hline \multirow[t]{4}{*}{ Educational level } & Illiterate & $112(26.9)$ \\
\hline & Primary & $21(5.0)$ \\
\hline & Secondary & $76(18.3)$ \\
\hline & Tertiary & $207(49.8)$ \\
\hline \multirow[t]{5}{*}{ Occupation } & House wife & $14(3.3)$ \\
\hline & Peasant/agriculture & $117(28.1)$ \\
\hline & Employed & 141(33.9) \\
\hline & Business/shop & $79(19.1)$ \\
\hline & Student & $65(15.6)$ \\
\hline \multirow{2}{*}{$\begin{array}{l}\text { Previous malaria } \\
\text { infection }\end{array}$} & Yes & $154(37)$ \\
\hline & No & $262(63)$ \\
\hline Time of last malaria & 2-6 months & $18(11.7)$ \\
\hline \multirow[t]{2}{*}{ Episode } & $>6$ months & $84(54.5)$ \\
\hline & Don't remember the time & $52(33.8)$ \\
\hline \multirow{4}{*}{$\begin{array}{l}\text { Anti-malaria drug taken } \\
\text { during last episode } \\
\text { Use of bed net }\end{array}$} & Yes & $151(98.1)$ \\
\hline & No & $3(1.9)$ \\
\hline & Yes & $152(36.5)$ \\
\hline & No & $264(63.5)$ \\
\hline \multirow{5}{*}{$\begin{array}{l}\text { Previous history of blood } \\
\text { donation } \\
\text { Number of previous } \\
\text { donations }\end{array}$} & Yes & $219(52.6)$ \\
\hline & No & $197(47.4)$ \\
\hline & Once & $124(56.6)$ \\
\hline & 2-4 times & $78(35.6)$ \\
\hline & $>4$ times & $17(7.8)$ \\
\hline \multirow[t]{4}{*}{ ABO blood group } & $\mathrm{O}$ & $175(42.1)$ \\
\hline & A & $136(32.7)$ \\
\hline & B & $87(20.9)$ \\
\hline & $\mathrm{AB}$ & $18(4.3)$ \\
\hline \multirow[t]{2}{*}{ Rh blood group } & $\mathrm{Rh}^{+}$ & $386(92.8)$ \\
\hline & $\mathrm{Rh}^{-}$ & $30(7.2)$ \\
\hline
\end{tabular}

The overall malaria prevalence in this study was 4.1\% (17/416). Eight and 9 donors were infected with $P$. falciparum and $P$. vivax respectively.
Most frequently detected developmental stages were early trophozoites $(14 / 17)$ (Table 2$)$.

DOI: http://dx.doi.org/10.4314/ejhs.v28i3.9 
Table 2: Stages of malaria parasites identified and parasite load among blood donors attending Arba Minch blood bank from February to June 2015

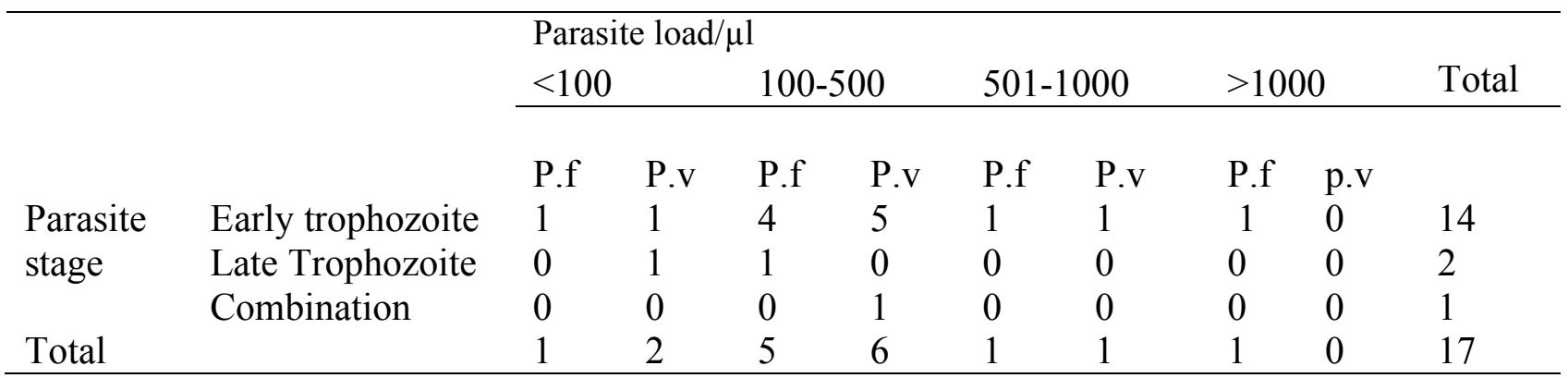

P.f: Plasmodium falciparum; P.v; plasmodium vivax

Higher proportion of females $(6.0 \%, 11 / 183)$ were infected than males $(2.6 \%, 6 / 233)$, but the difference was not statistically significant $(p=0.091)$. Asymptomatic malaria cases were higher among donors who did not use bed net compared to those who used $(\mathrm{p}=0.047)$. Donors with no previous history of donation had higher probability of getting infected than those attending for the first time $(p=0.022)$. Among plasmodium infected donors, the majority (14/17) were with blood group $\mathrm{O}$. Group $\mathrm{O}$ donors were more affected ascompared to other $\mathrm{ABO}$ blood groups together $(\mathrm{p}=0.003)$ (Table 3$)$.

\section{DISCUSSION}

The magnitude of asymptomatic malaria parasitemia in this study goes in line with findings from Sudan (6.5\%) (16). However, it was higher compared to similar studies from North Ethiopia $(1 \%, 6 / 600)$ (26). The difference might be, in part, due to low adherence to malaria prevention tools as only $11.8 \%$ of malaria positive donors slept under bed net although all lived in malaria endemic areas. Its implication is enormous when viewed from the recipients' side who are already weakened by existing severe diseases. Immunized individuals in malaria endemic areas may be asymptomatic carriers of plasmodium parasites even for a long period. However, this does not necessarily ensure lack of infectivity. Malaria parasites can survive in stored blood at refrigerator temperature $\left(+2^{0} \mathrm{C}\right.$ to $\left.+6^{0} \mathrm{C}\right)$ for days or weeks (27). Furthermore, the large volume of blood transfused enables large number of parasites to be transferred to recipients. Malaria thus behaves very aggressively in recipients with a higher risk of complications and fatalities. Asymptomatic carriers of the parasite also serve as sources of infection for the general population.

Our findings show approximately comparable distribution of $P$. falciparum and $P$. vivax. Plasmodium falciparum was the predominant species identified from infected donors according to a study from Sudan $(98.1 \%)$ (16). This difference might be because of variations in distribution of the species between countries. According to a recent WHO report, $P$. falciparum accounts for $95 \%$ in Sudan; but that of Ethiopia is $64 \%$ for $P$. falciparum and $36 \%$ for $P$. vivax (1). Relapse may also increase the frequency of $P$. vivax detection. As expected from asymptomatic carriers, 16 out of 17 positive blood films show light infection $(<1000$ parasites $/ \mu \mathrm{l})$ which is in line with findings from Sudan (16).

Regarding the factors associated with asymptomatic plasmodium parasitemia, females were more susceptible than males; but the variation was not statistically significant. Bivariate analysis also showed that donors who did not sleep under bed net $(\mathrm{p}=0.047)$ and had no previous history of blood donation $(\mathrm{p}=0.022)$ were more susceptible for asymptomatic malaria parasitemia as compared to those who slept under bed net and had history of donation respectively. The role of confounding factors should be considered here as there was no significant association for both variables in the 
Table 3: Association of malaria parasitemia with different independent variables among blood donors attending Arba Minch blood bank from February to June 2015

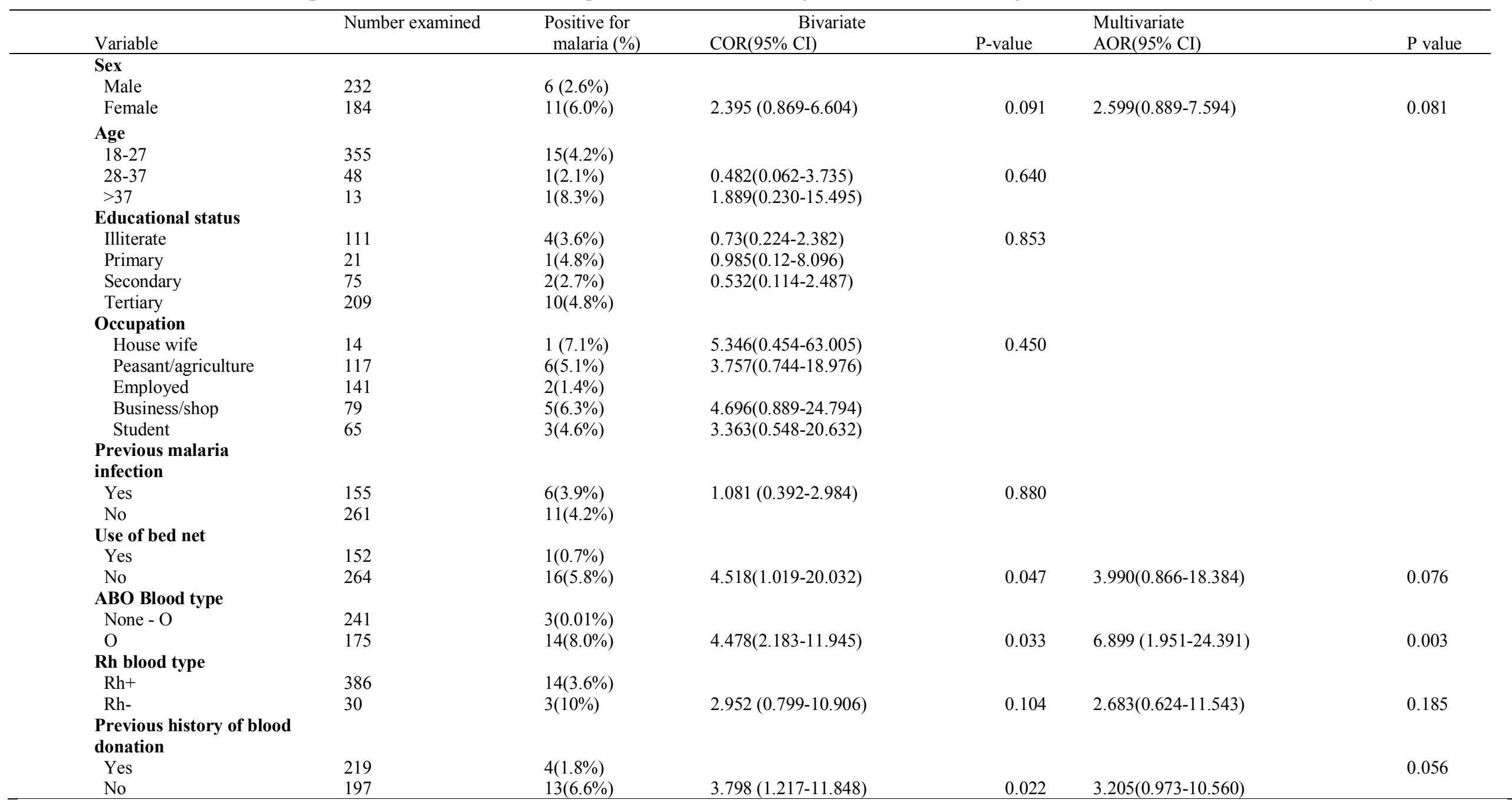

$\mathrm{p} \leq 0.05$ was taken as statistically significant at $95 \%$ confidence level: $\mathrm{CI}$; confidence interval

DOI: http://dx.doi.org/10.4314/ejhs.v28i3.9 
multivariate analysis. Blood group $\mathrm{O}$ donors were more susceptible to plasmodium infection than non-group $\mathrm{O}$ donors. This goes in line with findings from recent studies conducted in Nigeria $(14,28)$. Contrasting results have been reported in two studies in Nigeria again where $37.5 \%$ and $100 \%$ of the cases were with blood group $\mathrm{AB}$ $(12,29)$. According to studies by Sirina and Clement (18) and Otajevwo (28), ABO blood groups were not significantly associated with malaria infection rate. Complexity of the interaction between the parasites and host immune responses as well as impact of other red blood cell polymorphisms might be responsible for such differences.

This study had certain limitations related to the time of data collection and laboratory techniques used. The malaria prevalence would have been much higher if the data was collected during the major malaria transmission season (September to December). Sub-microscopic parasitemia is also common in asymptomatic carriers so that use of more sensitive diagnostic tests (molecular techniques) would yield higher rate of malaria parasitemia. This is evidenced by findings from Ghana that a prevalence of $4.7 \%$ by microscopy increased to $18 \%$ when diagnosed using polymerase chain reaction (17).

In conclusion, there is considerable prevalence of malaria parasites among blood donors attending Arba Minch blood bank. Hence, donations should be screened for malaria prior to release to inventory and, if not excluded, positive donors should be treated before being accepted for donation.We recommend large scale studies by recruiting more numbers of donors in order to conclude on the association between asymptomatic malaria and $\mathrm{ABO}$ blood group.

\section{ACKNOWLEDGEMENTS}

We thank health professionals working inArba Minch blood bank for their contribution during data collection, and Arba Minch University for funding the research. We are grateful to ethical review boards of Arba Minch University for giving ethical clearance. Our regards also go to the study subjects for giving consent to participate in the study.

\section{REFERENCES}

1. World Health Organization. World malaria report. Geneva 2016.

2. Malaria.http://www.who.int/topics/malaria/en/ Accessed on January 22/01/2017

3. Wariso KT, Oboro IL. Prevalence of plasmodium parasitemia among blood donors in Port Harcourt, Nigeria. Advances in microbiology. 2015;5:351-357.

4. Greenwood BM, Fidock DA, Kyle DE, Stefan HI. Malaria progress, perils, and prospects for eradication. Journal of Clinical Investigation. 2008;118(4):1266-1276.

5. Guerra CA, Gikandi PW, Tatem AJ, Noor AM. The limits and intensity of Plasmodium falciparum transmission: Implication formalaria control and elimination worldwide. PLoS Med. 2008;5:1329-1335.

6. Mwine J, Van Damme P, Jumba F. Evaluation of larvicidal properties of the latex of Euphorbia tirucalli L. (Euphorbiaceae) against larvae of Anopheles mosquitoes. J Med Plan Res. 2010;4:1953-1954.

7. Baume CA, Reithinger R, Woldehanna S. Factors associated with use and non use of mosquito nets owned in Oromia and Amhara Regional states, Ethiopia. Malaria Journal. 2009;8:258-264.

8. Amare D, Fessehaye A, Zewdie B, Abebe E. Effect of training on the use of long-lasting insecticidetreated bed nets on the burden of malaria among vulnerable groups, south-west Ethiopia: baseline results of a cluster randomized trial. Malaria Journal. 2010;9:119-121.

9. World Health Organization malaria fact sheet updated April 2017 http://www.who.int/mediacentre/factsheets/fs0 94/en/accessed on 20 June, 2017.

10. Brouwer EE, Van Hellemond JJ, Van Genderen PJJ, et al. A case report of transfusion-transmitted Plasmodium malariae from an assymptomatic non-immune traveller. Malaria Journal. 2013;12:439.

11. Badger-Emeka L, Emeka P, Egbu V. Prevalence of malaria plasmodium parasite among blood donors at Ntukka area, southeast

DOI: http://dx.doi.org/10.4314/ejhs.v28i3.9 
Nigeria. International journal of humanities, arts, medicine and science. 2013;1:45-50.

12. Oche AO, Aminu M. The prevalence of malarial parasitaemia among blood donors in Ahmadu Bello University Teaching Hospital, Shika, Zaria, Nigeria. Nig $J \mathrm{Med}$. 2012;21(4):445-449.

13. Oladeinde BH, Omoregie R, Osakue EO,et al. Asymptomatic Malaria among Blood Donors in Benin City Nigeria. Iranian $J$ Parasitol. 2014;9(3):415-422.

14. Epidi TT, Nwani CD, Ugorji NP. Prevalence of malaria in blood donors in Abakaliki Metropolis, Nigeria. Scientific Research and Essay. 2008;3(4):162-164.

15. Kinde-Gazard, Oke J, Gnahoui I, Massougbodji A. The risk of malaria transmission by blood transfusion at Cotonou, Benin. Sante. 2000;10:389-392.

16. Siddig MM, Ali A, Gader MA, Kadaru Y. Screening blood donors for malaria parasite in Sudan. Ethiop J Health Dev. 2004;18(2):7074.

17. Owusu-Ofori AK, Betson M, Parry CM, Stothard JR, Bates I. Transfusion-transmitted malaria in Ghana. Epub. 2013;56 (12):17351741.

18. Sirina Muntaka, Clement Opoku-Okrah. The Prevalence of Malaria Parasitaemia and Predisposition of ABO Blood Groups to Plasmodium falciparum Malaria among Blood Donors at a Ghanaian Hospital. $A U J T$. 2013;16(4):255-260.

19. Yadav P, Cohen JL, Alphs S, Arkedis J, Larson PS, Massaga J. Trends in availability and prices of subsidized ACT over the first year of the AMFm: evidence from remote regions of Tanzania. Malar Journal. 2012;11:299.

20. World Health Organization. World Malaria Report . Geneva 2012.

21. World Health Organization. Screening donated blood for transmission-transmissible infections: Recommendations. Geneva 2010.

22. World Health Organization Regional Office For

Africa:

http://www.afro.who.int/en/ethiopia/country- programmes/topics/4580-ethiopiamalaria.html. Accessed on July 04/07/2017.

23. Astatkie A. Knowledge and Practice of Malaria Prevention Methods Among Residents of Arba Minch Town and Arba Minch Zuria District, Southern Ethiopia. Ethiop J Health Sci. 2010;20(3):185-193.

24. Monica Cheesbrough. District Laboratory Practice in Tropical Countries Part $12^{\text {nd }}$ ed. Cambridge University Press, New York, 1998: 239-258.

25. Andrew OF, Robert Damoiseaux, Sarah Grundeen. Quantitative detection of PfHRP2 in saliva of malaria patients in the Philippines. Malaria Journal. 2012;11(175): http://www.malariajournal.com/content/11/11/ 175.

26. Baye G, Yohannes M. The prevalence of $\mathrm{HBV}, \mathrm{HCV}$ and malaria parasites among blood donors in Amhara and Tigray Regional states. Ethiop J Health Dev. 2007;22(1):3-7.

27. Uneke CJ, Ogbu O, Nwojiji V. Potential risk of induced malaria by blood transfusion in South-eastern Nigeria. Mcqill JMed. 2006;9: 8-13.

28. Otajevwo FD. ABO Blood groups Association with malaria parasitaemia among residents in Warri, Delta State. Warri Journal of Science and Technology. 1997;4(1):32-35.

29. Ilozumba PC, Uzozie CR. Prevalence of malaria parasitaemia and its association with ABO Blood Group in Odoakpu Area of Onitsha South Local Government Area, Anambra State Nigeria. Nigerian Annals of Natural Sciences. 2009;8(2):1- 8.

DOI: http://dx.doi.org/10.4314/ejhs.v28i3.9 